\title{
Propriedades físicas do solo em sistema de integração lavoura-pecuária em Cambissolo Húmico
}

\author{
Physical soil properties in crop-livestock integration system in Humic Cambisol
}

\section{Diego Bortolini*, Jackson Adriano Albuquerque, Cléber Rech, Álvaro Luiz Mafra, Henrique Mendonça Nunes Ribeiro Filho e Patrícia Pértile}

Recebido em 15/07/2015 / Aceito em 27/11/2015.

\section{RESUMO}

Em sistema de integração lavoura-pecuária associado ao sistema de semeadura direta, a ação do pisoteio animal pode influenciar as propriedades físicas do solo, dependendo da intensidade de pastejo e da carga animal. O presente trabalho objetivou avaliar as propriedades físicas de um Cambissolo Húmico, sob sistema de integração lavoura-pecuária submetido a diferentes intensidades de pastejo de gado leiteiro, no município de Lages, SC. Os tratamentos foram constituídos por pastejo direto de gado em três disponibilidades de forragem do consórcio de aveia e azevém (baixa, média e alta) e uma testemunha, sem pastejo. Foram avaliados densidade, propriedades hidráulicas, teor de matéria orgânica, agregação e resistência à penetração do solo. De maneira geral, o pisoteio animal não influenciou significativamente as propriedades físicas, a dinâmica da água e os teores de matéria orgânica do solo. As condições de macroporosidade, bem como a resistência à penetração, principalmente em condição de baixa umidade, demonstram que o Cambissolo Húmico de textura franco argilo siltosa possui restrições físicas ao desenvolvimento das plantas.

PALAVRAS-CHAVE: sistema de semeadura direta, manejo do solo, cobertura do solo, matéria orgânica do solo.

\begin{abstract}
In integrated crop-livestock systems under a no-tillage system, the action of animal trampling can influence the physical properties of the soil, depending on the intensity of grazing and stocking rate. This study aimed to evaluate the physical properties of a Humic Cambisol, under an integrated crop-livestock system
\end{abstract}

submitted to different grazing intensities of lactating cows in the city of Lages, SC. The treatments constituted three forage masses of winter pasture (low, medium and high), and a control area, with no grazing (no grazing), oat and ryegrass consortium was used, then the density, hydraulic properties of the soil, organic matter content, aggregation and soil penetration resistance were evaluated. Generally the animal trampling had no significant influence on physical properties, the dynamics of water and the contents of soil organic matter. The macroporosity conditions, as well as high resistance to penetration, principally in conditions of low moisture, prove that the Humic Cambisol of the franc silty clay texture provides a constraint physical problem.

KEYWORDS: No-tillage system, soil management, soil cover, soil organic matter.

\section{INTRODUÇÃO}

A integração lavoura-pecuária em sistema de semeadura direta (SSD) é um sistema muito promissor em várias regiões do Brasil, no entanto preocupa técnicos e agricultores devido a possibilidade de compactação do solo na camada superficial (COLLARES 2005), bem como pela baixa massa residual que as forrageiras de inverno proporcionam ao cultivo subsequente, quando mal manejadas (MOREIRA et al. 2014).

A ação do pisoteio e o pastejo intensivo sobre o solo, em sistemas conservacionistas, pode reduzir o aporte de material orgânico e o estoque de matéria orgânica do solo, com consequências na agregação do solo. Somado a isso, a densidade do solo aumenta e a porosidade total diminui, principalmente quando o pisoteio e o trânsito de máquinas ocorre quando o solo está com a consistência plástica (DIAS JUNIOR \&

Universidade do Estado de Santa Catarina, Lages, SC, Brasil.

*Autor para correspondência < diegobertanbortolini@gmail.com>. 
PIERCE 1996, SILVA et al. 2002). Este processo reduz principalmente a macroporosidade (BALBINOT et al. 2009), e altera a distribuição do tamanho dos poros e a retenção de água no solo (MORAES 1984, HILLEL 1998). Além destas modificações, eleva a resistência mecânica à penetração do solo (MORAES 1984, HILLEL 1998).

Entretanto, a compactação excessiva pode limitar a absorção de nutrientes, infiltração e redistribuição de água, trocas gasosas e desenvolvimento do sistema radicular (SMUCKER \& ERICKSON 1989) resultando em decréscimo da produção, aumento da erosão e da potência necessária para o preparo do solo (SOANE 1990). Por outro lado, embora esporadicamente, alguns estudos indicam que a compactação do solo pode ter efeitos benéficos, atribuídos à melhoria do contato solo-semente (SMUCKER \& ERICKSON 1989) e ao aumento da disponibilidade de água em anos secos (RAGHAVAN \& MICKYES 1983).

Com todas estas modificações no solo, o sistema de integração lavoura-pecuária (SILP) tem resultados muito variados. MOREIRA et al. (2014) encontraram influência do SILP nas propriedades físicas do solo, em Latossolo Vermelho, após sete anos de SILP no sistema mais intensivo de pastejo, com redução da macroporosidade e aumento da densidade. BORTOLINI et al. (2013), também em Latossolo Vermelho de textura muito argilosa, não observaram influências da intensidade de pastejo com caprinos em papuã, em propriedades físicas e teor de matéria orgânica do solo, no primeiro ciclo de pastejo, o que pode não ter sido suficiente para detectar diferenças nas propriedades avaliadas. Esta variabilidade de resultados observados se deve principalmente às condições específicas de cada local avaliado (condições edafoclimáticas), e intrínsecas do SILP utilizado (espécie animal, pastagem, cultura de grãos, carga animal, adubação, duração do período de pastejo, etc.).

$\mathrm{O}$ presente trabalho objetivou avaliar as propriedades físicas de um Cambissolo Húmico, sob sistema de integração lavoura-pecuária submetido a diferentes intensidades de pastejo de gado leiteiro, no município de Lages, SC.

\section{MATERIAL E MÉTODOS}

O experimento foi implantado na área experimental da UDESC-CAV no município de Lages - SC, onde o solo é classificado como Cambissolo Húmico (EMBRAPA 2013), com relevo suave ondulado a ondulado. A textura é franco argilo siltosa (Tabela 1), analisado através de método descrito por DAY (1965), e densidade de partículas média de $2,55 \mathrm{Mg} \mathrm{m}^{-3}$, analisado por método descrito em EMBRAPA (2011). A área experimental vem sendo cultivada no SSD e SILP desde 2008, semeando-se no inverno pastagem consorciada de aveia (Avena strigosa) e azevém (Lolium multiflorum). Nas safras de verão 2010/11, 2011/12 e 2012/13 a área foi cultivada com milho (Zea mays), sendo o mesmo também cultivado nas duas safras de verão anteriores ao início do experimento (2008/09 e 2009/10).

Os tratamentos foram constituídos por três massas de forragem de pastagem de inverno denominadas como: baixa (1.300 kg MS ha-1), média $\left(1.400 \mathrm{~kg} \mathrm{MS} \mathrm{ha}^{-1}\right)$ e alta $\left(1.600 \mathrm{~kg} \mathrm{MS} \mathrm{ha}^{-1}\right)$, e uma área testemunha, a qual não houve pastejo (sem pastejo). $\mathrm{O}$ delineamento experimental utilizado foi em blocos ao acaso com três repetições. O método de pastejo utilizado foi o rotativo, sendo que as parcelas foram pastejadas em três períodos até que fossem atingidas as massas de forragem de cada tratamento. Nos períodos entre pastejo os animais (vacas leiteiras) foram suplementados diariamente com $4 \mathrm{~kg}$ de

Tabela 1 - Caracterização granulométrica e de densidade de partícula da área experimental.

Table 1 - Characterization of particle size and particle density of the experimental area.

\begin{tabular}{ccccc}
\hline Camada do solo (m) & Areia & $\begin{array}{c}\text { Silte } \\
\text { 0 a } 0,05\end{array}$ & Argila & $\begin{array}{c}\mathrm{Dp}^{1} \\
\mathrm{Mg} \mathrm{m}^{-3}\end{array}$ \\
0,05 a 0,10 & 200 & 450 & 350 & 2,51 \\
0,10 a 0,20 & 190 & 450 & 360 & 2,57 \\
Média & 180 & 450 & 370 & 2,58 \\
\hline
\end{tabular}

${ }^{1} \mathrm{Dp}$ : densidade de partículas 
matéria seca de silagem de milho e $0,6 \mathrm{~kg}$ de matéria seca de farelo de soja. Duas vezes em cada ciclo de pastejo, durante o ciclo do consórcio de pastagens, foram avaliadas as intensidades de pastejo através do uso de um prato ascendente (Farmworks ${ }^{\circledR}$, F200 model, New Zealand), e por coleta em cinco pontos em cada parcela do material vegetal em área de $1 \mathrm{~m}^{2}$, sendo estes secos em estufa a $60{ }^{\circ} \mathrm{C}$ por $72 \mathrm{~h}$, para determinar o teor de matéria seca. Após foram ajustadas equações de regressão para a massa do pasto em função da altura do mesmo $\left(\mathrm{kg} \mathrm{MS} \mathrm{ha}^{-1}\right)$ ('T MANNETJE 2000).

Foi realizada coleta de solo no mês de novembro de 2011, 20 dias após a retirada dos animais. Nesta oportunidade foram coletadas amostras com estrutura preservada, nas camadas de 0 a $0,05,0,05$ a 0,10 e 0,10 a $0,20 \mathrm{~m}$ de profundidade, com anéis metálicos de $0,05 \mathrm{~m}$ de altura por $0,06 \mathrm{~m}$ de diâmetro. Também foram coletadas amostras com estrutura alterada, na forma de leivas, nas mesmas camadas acima citadas.

Nas amostras com estrutura preservada foi avaliada a retenção de água, sequencialmente em mesa de areia (mesa de tensão) e Extratores de Richards. $\mathrm{Na}$ mesa de areia foram aplicadas as tensões de 1, 6 e $10 \mathrm{kPa}$, e nos extratores de Richards as tensões de 33 e $100 \mathrm{kPa}$ (RICHARDS 1949). Após a pesagem das amostras na tensão $100 \mathrm{kPa}$, estas foram saturadas para determinar a condutividade hidráulica saturada com um permeâmetro de carga variável. Após, as amostras foram secas em estufa com circulação de ar à $105^{\circ} \mathrm{C}$, para determinação da densidade do solo. Com os dados de retenção de água foi gerada a curva de retenção de água no solo, sendo esta ajustada utilizando o modelo de VAN GENUTCHEN (1980), e também foram calculadas a macroporosidade (água retida a tensão de $6 \mathrm{kPa}$ ), microporosidade (diferença entre água retida a tensão de $6 \mathrm{kPa}$ e solo seco), porosidade total, capacidade de campo (água retida a tensão de $10 \mathrm{kPa}$ ), água prontamente disponível (diferença entre água retida a tensão de $10 \mathrm{kPa}$ e $100 \mathrm{kPa}$ ), além da densidade do solo. Nas amostras com estrutura alterada foram determinadas a distribuição de classes de agregados e diâmetro médio geométrico por Via Úmida Padrão (KEMPER \& CHEPIL 1965), e o teor de matéria orgânica total do solo pelo método de Walkley e Black, modificado por TEDESCO et al. (1995).

A resistência à penetração do solo à campo, na camada de 0-30 cm, foi avaliada em três épocas: após o período de pastejo animal em novembro de 2011, após a colheita do milho em abril de 2012 e após a colheita do milho em abril de 2013. Para isso foi utilizado penetrógrafo móvel da marca FALKER, modelo PenetroLog. Em cada unidade experimental foram realizadas oito determinações, com determinação concomitante da umidade gravimétrica.

Após determinar a homogeneidade da variância, independência e normalidade dos resíduos, a análise da variância (Anova) foi realizada separadamente para cada camada. Quando a Anova resultou em valor $p$ significativo $(\mathrm{p}<0,05)$, o teste de Tukey foi utilizado para comparação de médias entre os tratamentos.

\section{RESULTADOS E DISCUSSÃO}

De maneira geral as propriedades do solo relacionadas com a retenção de água e porosidade do solo não apresentaram diferenças significativas entre os tratamentos. A retenção de água entre os potenciais matriciais de 0 a $100 \mathrm{kPa}$ não apresentou diferenças significativas entre tratamentos nas três camadas de solo avaliadas. Isso indica que o pisoteio animal e o trânsito de máquinas no sistema de SILP não alterou significativamente a distribuição de tamanho dos poros e, consequentemente, a quantidade de água retida em todas as tensões analisadas (Figura 1). A macro e microporosidade e porosidade total do solo, capacidade de campo e água prontamente disponível, as quais juntamente com a densidade do solo, a condutividade hidráulica saturada e o diâmetro médio geométrico dos agregados não sofreram alterações significativas pelas distintas intensidades de pastejo (Tabela 2).

A porosidade total esteve abaixo de $0,50 \mathrm{~m}^{3} \mathrm{~m}^{-3}$, a microporosidade acima de $0,40 \mathrm{~m}^{3} \mathrm{~m}^{-3}$, a macroporosidade inferior a $0,10 \mathrm{~m}^{3} \mathrm{~m}^{-3}$ e a água prontamente disponível em torno de $0,03 \mathrm{~m}^{3} \mathrm{~m}^{-3}$. Estes valores indicam que este solo apresenta restrições ao crescimento e desenvolvimento de plantas, principalmente pela baixa macroporosidade do solo (BELTRAME et al. 1981), pois mesmo no tratamento sem pastejo há problemas. A condutividade hidráulica saturada não apresentou diferença significativa entre os tratamentos avaliados (Tabela 2), devido principalmente a alta variabilidade encontrada para esta variável.

A resistência à penetração diferiu apenas na camada de 0-1 cm na primeira avaliação (Figura 2a). 

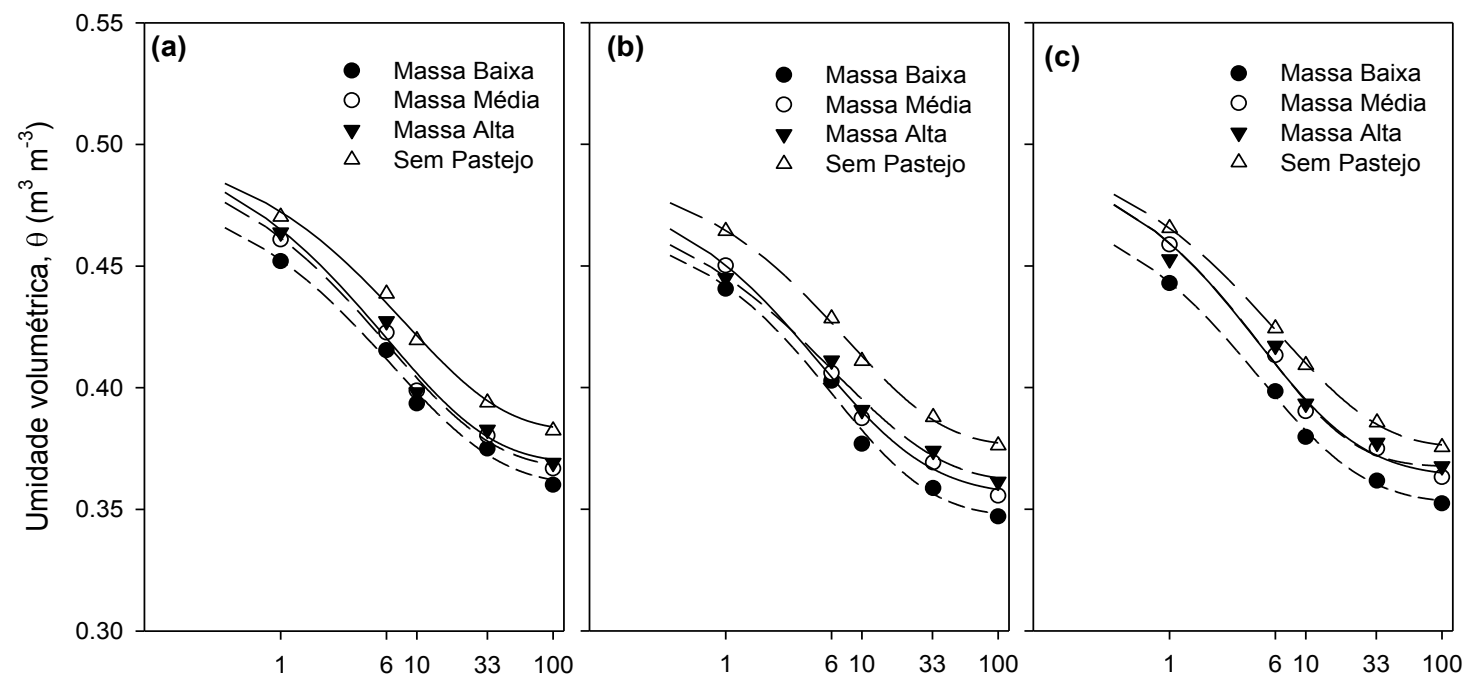

Potencial matricial, $\psi(\mathrm{kPa})$

Figura 1 - Retenção de água de um Cambissolo Húmico manejado em sistema de integração lavoura-pecuária com diferentes disponibilidades de forragem do consórcio de aveia + azevém, no município de Lages-SC. (a) $0-0,05 \mathrm{~m}$, (b) 0,05-0,1 m e (c) 0,1-0,2 m.

Figure 1 - Water retention of a Humic Cambisol in integrated crop-livestock area, managed under different masses of oat forage consortium + ryegrass, in Lages-SC. (a) from 0 to $0.05 \mathrm{~m}$, (b) 0.05 to $0.1 \mathrm{I}$ (c) from 0.1 to $0.2 \mathrm{~m}$.

Tabela 2 - Propriedades físicas de um Cambissolo Húmico manejado em sistema de integração lavoura-pecuária com diferentes disponibilidades de forragem do consórcio de aveia + azevém, no município de Lages-SC.

Table 2 - Physical properties of a Humic Cambisol, in integrated crop-livestock system area, managed under different masses of oat forage consortium + ryegrass, in Lages-SC.

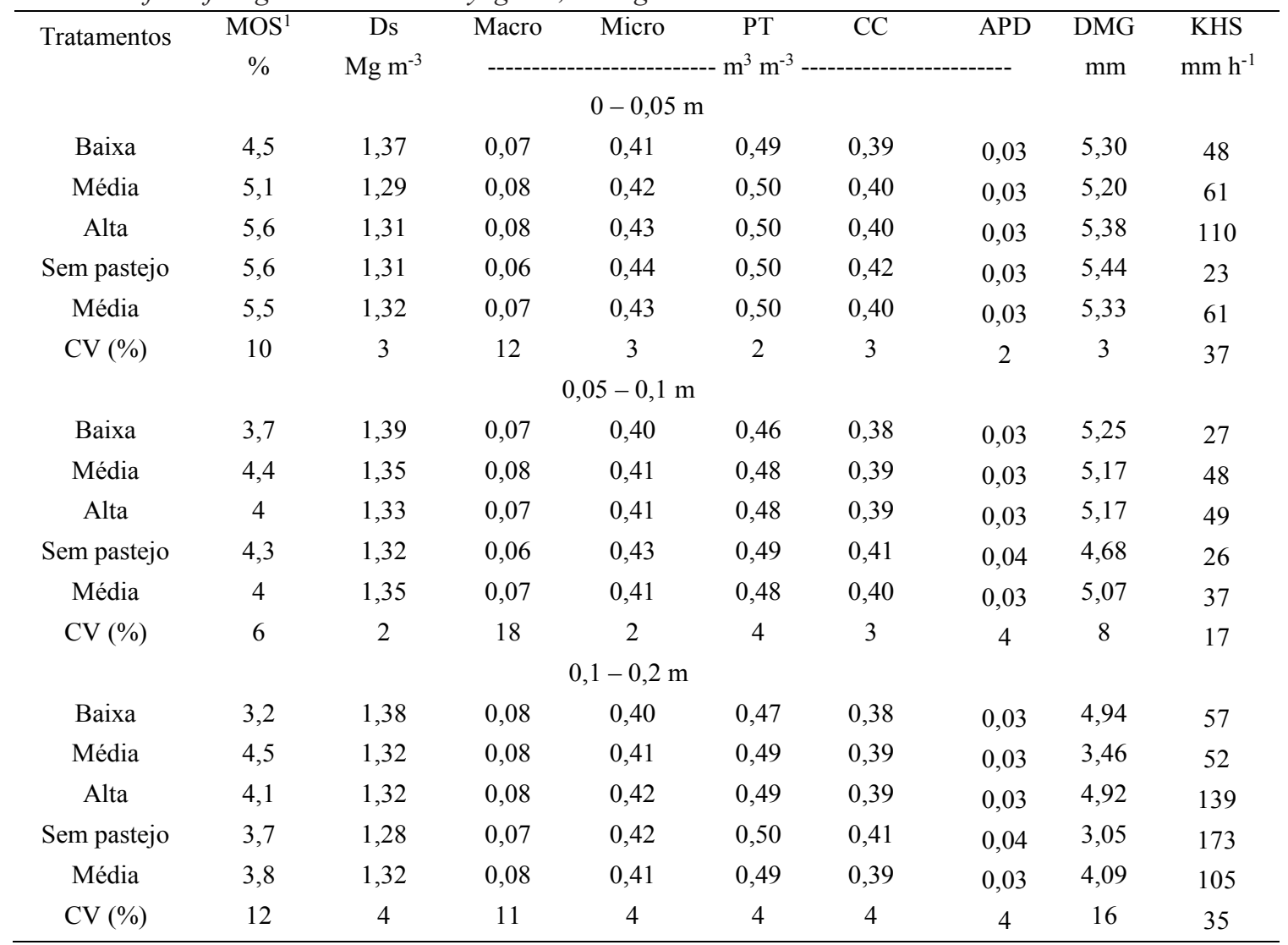

${ }^{1}$ MOS: matéria orgânica do solo, Ds: densidade do solo, Macro: macroporosidade, Micro: microporosidade, PT: porosidade total, CC: capacidade de campo, APD: água prontamente disponível, DMG: diâmetro médio geométrico, KHS: condutividade hidráulica saturada. 
Nesta camada, a resistência à penetração no sistema sem pastejo não diferiu da intensidade baixa de pastejo, porém diferiu dos demais tratamentos avaliados. O principal fator que causou variação da resistência à penetração entre as épocas avaliadas foi a umidade do solo, que na primeira avaliação foi de $0,22 \mathrm{~g} \mathrm{~g}^{-1}$, na segunda de $0,16 \mathrm{~g} \mathrm{~g}^{-1}$ e na terceira de $0,20 \mathrm{~g} \mathrm{~g}^{-1}$. Na segunda avaliação foram observados os menores valores de umidade e os maiores valores de resistência à penetração, com valores superiores a $2.000 \mathrm{kPa}$ a partir dos $4 \mathrm{~cm}$ de profundidade, que podem ser limitantes ao desenvolvimento das raízes das plantas (BENGHOUGH \& MULLINS 1990), quando há redução dos teores de água. Em Nitossolo Vermelho de textura argilosa, ALBUQUERQUE et al. (2001) encontraram redução no volume de macroporos e na condutividade hidráulica saturada na camada superficial de solo sob SSD com pastejo direto, em decorrência do trânsito de máquinas e implementos agrícolas utilizados na semeadura do milho e ao pisoteio animal no período de inverno. LANZANOVA et al. (2007), em um Argissolo Vermelho-Amarelo de textura franco siltosa, verificaram que o pisoteio intenso de animais em área de SILP reduz a macroporosidade na camada superficial do solo.

Os resultados quanto à interferência do pisoteio animal nas propriedades físicas do solo são diversos e dependem muito de vários fatores, como aspectos ligados às condições climáticas, às espécies animal e vegetal, às condições edáficas, à carga animal utilizada e ao tempo de uso do sistema. ARATANI et al. (2009) concluíram que a utilização do SILP em Latossolo Vermelho com textura muito argilosa, não altera a qualidade física do solo no seu primeiro ano de inclusão no sistema, indicando que o sistema não difere do SSD sem pastejo direto. No estudo de ALBUQUERQUE et al. (2001), os autores observaram que a degradação física do solo no SILP prejudicou o crescimento e a produtividade do milho quando comparado ao SILP com preparo convencional para implantação da cultura de verão, o que foi explicado pelo fato de o preparo do solo eliminar ou diminuir os efeitos da compactação causada pelo pisoteio e trânsito de máquinas.

COSTA et al. (2009) não observaram diferenças na densidade em um Cambissolo Húmico de textura franco argilosa conduzido em SSD com pastejo e sem pastejo e observaram que as propriedades físicas do solo podem ser mantidas, desde que utilizado manejo adequado da pastagem. SPERA et al. (2006) e SPERA et al. (2009) também não encontraram diferenças nos atributos físicos em um Latossolo Vermelho que pudessem restringir a produção vegetal.

LAZANOVA et al. (2007) em trabalho sobre Argissolo Vermelho-Amarelo, verificaram

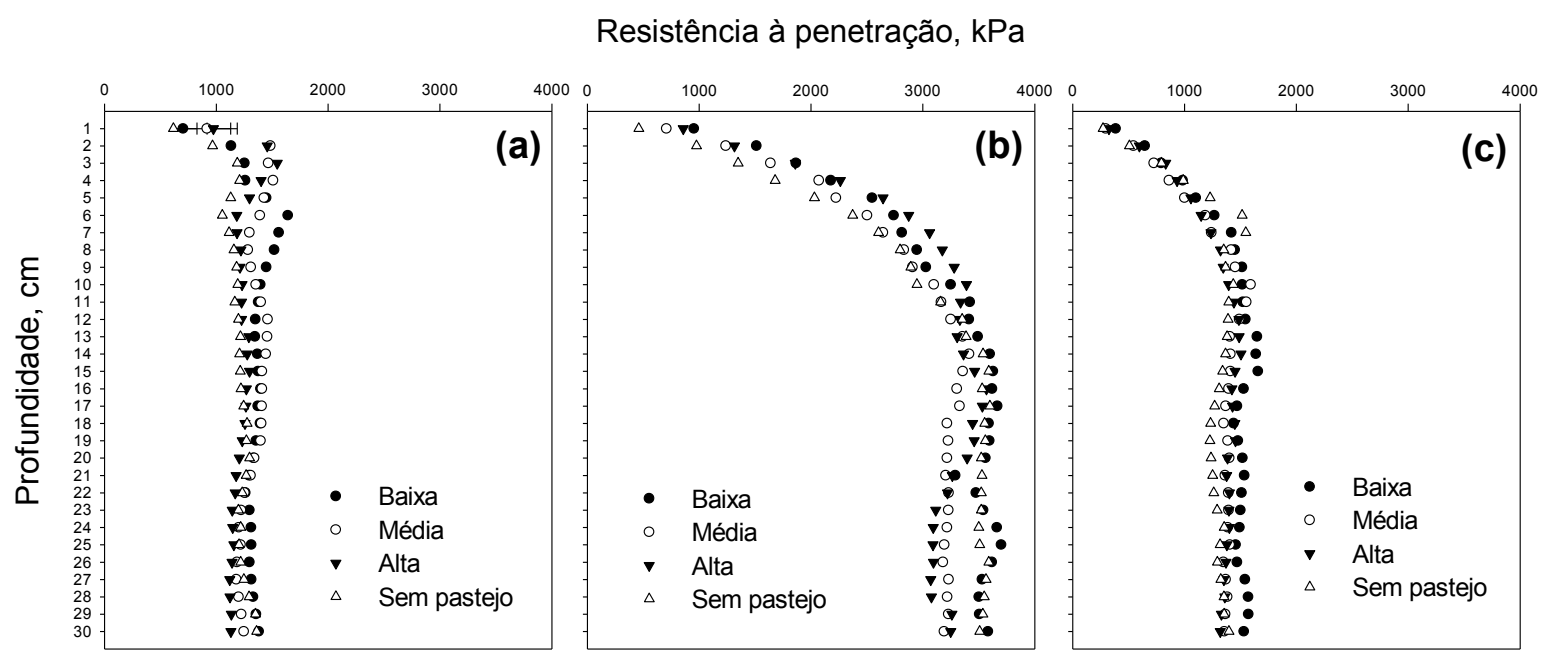

Figura 2 - Resistência à penetração de um Cambissolo Húmico manejado em sistema de integração lavourapecuária com diferentes disponibilidades de forragem do consórcio de aveia + azevém em (a) novembro de 2011, (b) abril de 2012 e (c) abril de 2013.

Figure 2 - Resistance to penetration of a Humic Cambisol under different grazing intensities in oats and ryegrass in integrated crop-livestock area of (a) November 2011; (b) in April 2012 and (c) in April 2013. 
que o pisoteio intenso de animais em área de SILP compacta a camada superficial, com aumento da densidade do solo na camada 0 a $0,05 \mathrm{~m}$ e redução da macroporosidade e porosidade total do solo, respectivamente, nas camadas 0 a $0,15 \mathrm{~m}$ e 0 a $0,20 \mathrm{~m}$ de profundidade.

Nas condições estudadas não há evidências de que o pisoteio tenha interferido negativamente nas propriedades físicas mesmo havendo restrição à macroporosidade do solo, já que ela foi identificada também no tratamento sem pastejo e, portanto, se deve a outros fatores e não a influência do pisoteio animal.

Com relação aos atributos de estabilidade dos agregados, não foram detectadas diferenças significativas na DMG (Tabela 2), classes de tamanho de agregados $>4,75 \mathrm{~mm}, 2 \mathrm{~mm}$ e $<0,25 \mathrm{~mm}$ em todas as camadas avaliadas (Figuras $3 \mathrm{a}$ e $3 \mathrm{~b}$ ). Entretanto, observou-se diferença significativa para as classes de agregados de $1,0 \mathrm{~mm}$ e $0,25 \mathrm{~mm}$ na camada de solo
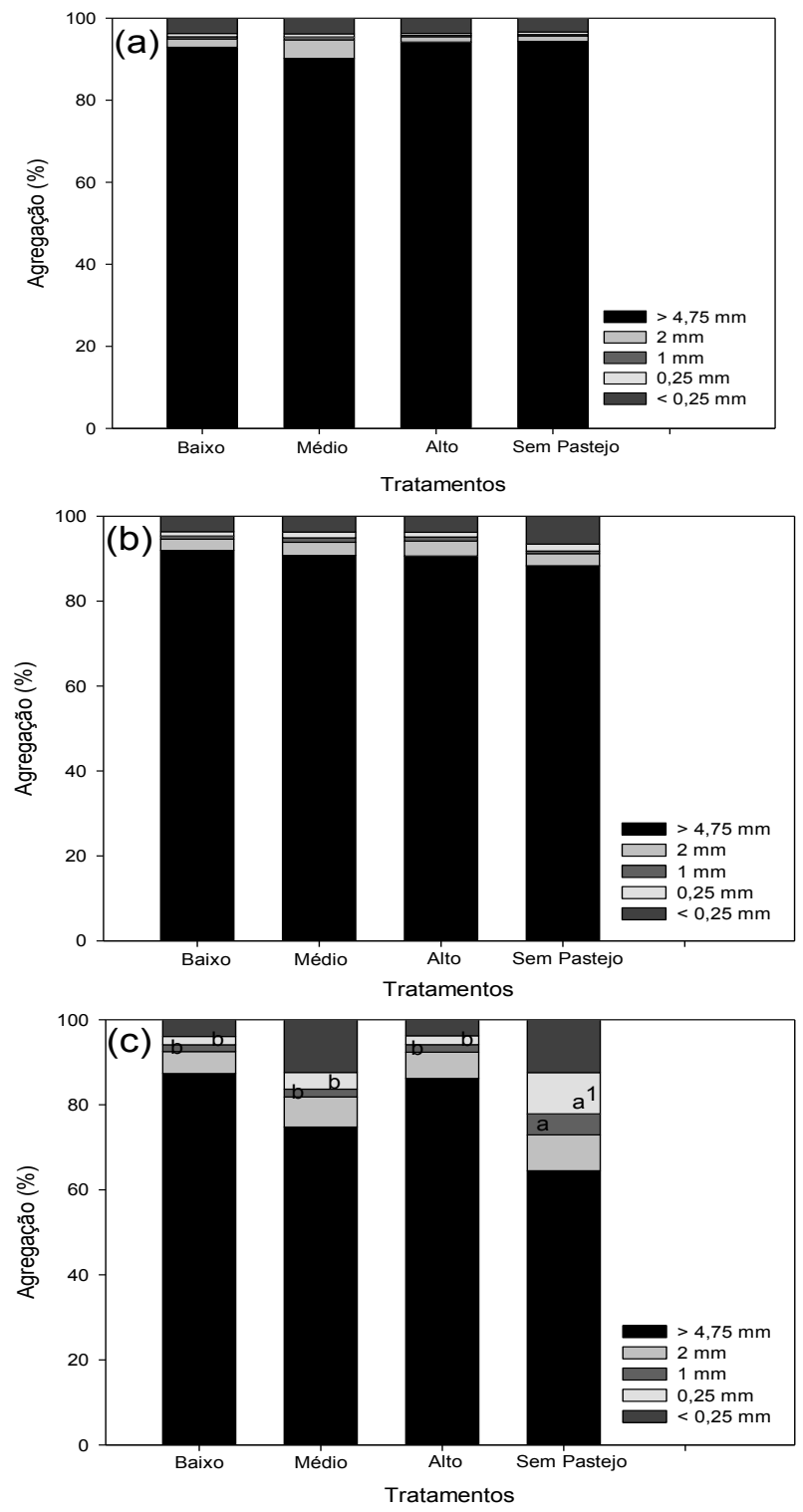

Figura 3 - Participação percentual das classes de tamanho de agregados de um Cambissolo Húmico manejado em sistema de integração lavoura-pecuária com diferentes disponibilidades de forragem de consórcio de aveia + azevém, no município de Lages-SC. (a) 0 - 0,05 m, (b) 0,05-0,1 m e (c) 0,1 a 0,2 m.

As médias dentro da mesma classe de tamanho de agregados não ligadas pela mesma letra diferem a $5 \%$ de probabilidade de erro pelo teste de Tukey.

Figure 3 - Aggregate size classes of a Humic Cambisol in integrated crop-livestock area, managed under different masses of oat forage consortium + ryegrass, in Lages-SC. (a) $0-0.05 \mathrm{~m}$, (b) $0.05-0.1 \mathrm{~m}$ and (c) 0.1 to $0.2 \mathrm{~m}$.

Means within the same aggregate size class not bound by the same letter differ at 5\% error probability by Tukey test. 
de $0,10,2 \mathrm{~m}$ (Figura 3c). A maioria dos agregados permaneceu na classe de tamanho $>4,75 \mathrm{~mm}$, evidenciando a alta estabilidade dos agregados em todos os tratamentos e em todas as camadas avaliadas neste estudo. Nas classes de tamanho de agregados de $1,0 \mathrm{~mm}$ e $0,25 \mathrm{~mm}$ na camada de solo de $0,1,0,2 \mathrm{~m}$, o tratamento sem pastejo diferiu significativamente dos demais, tendo maior percentagem de agregados naquele tratamento do que nos demais.

SOUZA (2008), estudando diferentes alturas de manejo de pastagem de aveia e azevém cultivada num Latossolo Vermelho distroférrico, relatou maior agregação sob pastejo moderado, além do aumento do diâmetro médio ponderado dos agregados (DMP) com o tempo de pastejo nas camadas de $0,05,0,1 \mathrm{~m}$ e 0,1 , 0,2 m. ARATANI et al. (2009), estudando diferentes sistemas de manejo em Latossolo Vermelho, não constataram efeito do uso do SILP em índices de agregação do solo, o que foi atribuído ao pouco tempo de adoção do sistema, não permitindo a expressão das características positivas do uso desse sistema, bem como por ainda não ter sido observadas alterações nos teores de matéria orgânica do solo. Este aspecto também pode ser verificado neste trabalho, onde ainda não houve alterações significativas nos teores de matéria orgânica do solo nos distintos tratamentos de intensidade de pastejo.

\section{CONCLUSÕES}

O pisoteio animal não influenciou de forma significativa as propriedades físicas, a dinâmica da água e os teores de matéria orgânica do solo no Cambissolo Húmico de textura franco argilo siltosa usado neste estudo. No entanto, este solo apresenta valores de macroporosidade próximos aos limitantes, com densidade do solo alta, além de alta resistência à penetração.

\section{AGRADECIMENTOS}

Ao Apoio do projeto CNPq REPENSA/562688/2010-2, CAPES, FAPESC e UDESC.

\section{REFERÊNCIAS}

ALBUQUERQUE JA et al. 2001. Efeitos da integração lavoura-pecuária nas propriedades físicas do solo e características da cultura do milho. Rev. Bras. Ciênc. Solo. 25: 717-723.

ARATANI RG et al. 2009. Qualidade física de um
Latossolo Vermelho acriférrico sob diferentes sistemas de uso e manejo. Rev. Bras. Ciênc. Solo. 33: 677-687.

BALBINOT AA et al. 2009. Integração lavoura-pecuária: intensificação de uso de áreas agrícolas. Ciênc. Rural. 39: 1925-1933.

BELTRAME LFS et al. 1981. Estrutura e compactação na permeabilidade de solos do Rio Grande do Sul. Rev. Bras. Ciênc. Solo 5: 145-149.

BENGHOUGH AG \& MULLINS CE. 1990. Mechanical impedance to root growth: a review of experimental techniques and root growth responses. J. Soil Sci. 41: 341358.

BORTOLINI D et al. 2013. Altura de manejo de papuã e propriedades de solo em sistema de integração lavourapecuária. Rev. Ceres. 60: 535-543.

COLLARES GL. 2005. Compactação em Latossolos e Argissolo e relação com parâmetros de solo e de plantas. Tese (Doutorado em Ciência do Solo). Santa Maria: UFSM. $107 \mathrm{p}$.

COSTA A et al. 2009. Propriedades físicas do solo em sistemas de manejo na integração agricultura-pecuária. Rev. Bras. Ciênc. Solo. 33: 235-244.

DAY PR. 1965. Particle fractionation and particle-size analysis. In BLACK CA et al. Methods of soil analysis. Part 1. Madison: American Society of Agronomy. p.545567.

DIAS JUNIOR MS \& PIERCE FJ. 1996. O processo de compactação do solo e sua modelagem. Rev. Bras. Ciênc. Solo. 20: 175-182.

EMBRAPA - EMPRESA BRASILEIRA DE PESQUISA AGROPECUÁRIA - Centro Nacional de Pesquisa de Solos. 2011. Manual de métodos de análise de solo. 2.ed rev. Rio de Janeiro: Embrapa. 230p.

EMBRAPA - EMPRESA BRASILEIRA DE PESQUISA AGROPECUÁRIA - Centro Nacional de Pesquisa de Solos. 2013. Sistema brasileiro de classificação de solos. 3.ed. Brasília: Embrapa. 353p.

HILLEL D. 1998. Environmental soil physics. San Diego: Academic Press. 771p.

KEMPER WD \& CHEPIL WS. 1965. Size distribution of aggregates. In: BLACK CA et al. Methods of soil analysis. Part 1. Madison: American Society of Agronomy. p.499510.

LANZANOVA ME et al. 2007. Atributos físicos do solo em sistema de integração lavoura-pecuária sob plantio direto. Rev. Bras. Ciênc. Solo. 31: 1131-1140.

MORAES WV. 1984. Comportamento de características e propriedades físicas de um Latossolo Vermelho-Escuro, submetido a diferentes sistemas de cultivo. Dissertação (Mestrado em Ciência do Solo). Lavras: UFLA. 107p.

MOREIRA WH et al. 2014. Influência da altura de pastejo de azevém e aveia em atributos físicos de um Latossolo Vermelho distroférrico, após sete anos sob integração lavoura-pecuária. Rev. Bras. Ciênc. Solo 38: 1315-1326. . RAGHAVAN GSV \& MICKYES E. 1983. Physical and 
hydraulic characteristics in compacted clay soils. Journal of Terramec. 19: 235-242.

RICHARDS L. 1949. Methods of measuring moisture tension. Soil Sci. 58: 95-112.

SILVA VR et al. 2002. Fatores controladores da compressibilidade de um Argissolo Vermelho-Amarelo distrófico arênico e de um Latossolo Vermelho distrófico típico. II - grau de saturação em água. Rev. Bras. Ciênc. Solo. 6: 9-15.

SMUCKER AJM \& ERICKSON AE. 1989. Tillage and compactive modifications of gaseous flow and soil aeration. In: LARSON WE et al (eds.). Mechanics related process in structured agricultural soils. Amsterdam: Kluwer Academic Publishers. v.172, p.205-221.

SOANE BD. 1990. The role of organic matter in soil compatibility: A review of some practical aspects. Soil Tillage Res. 16: 179-201.

SOUZA ED. 2008. Evolução da matéria orgânica, do fósforo e da agregação do solo em sistema de integração agricultura-pecuária em plantio direto, submetido a intensidades de pastejo. Tese (Doutorado em Ciência do Solo). Porto Alegre: UFRGS. 182p.

SPERA ST et al. 2006. Efeito de pastagens de inverno e de verão em características físicas de solo sob plantio direto. Ciênc. Rural. 36: 1193-1200.

SPERA ST et al. 2009. Integração lavoura e pecuária e os atributos físicos de solo manejado sob sistema plantio direto. Rev. Bras. Ciênc. Solo. 33: 129-136.

TEDESCO MJ et al. 1995. Análise de solo, plantas e outros materiais. Porto Alegre: Departamento de Solos - UFRGS. $174 \mathrm{p}$.

VAN GENUCHTEN MTA. 1980. Closed-form equation for predicting the hydraulic conductivity of unsaturated soils. Soil Sci. Soc. Am. J. 44: 892-898.

'T MANNETJE L. 2000. Measuring biomass of grassland vegetation. In: MANNETJE L'T \& JONES RM. Field a laboratory methods for grassland and animal production research'. Wallingford: CABI Publishing/CAB International. p.151-177. 